HEALTH PSYCHOLOGY REPORT · VOLUME 6(2), 2018 ORIGINAL ARTICLE
Rebecca Keyte

$1 \cdot \mathrm{A}, \mathrm{B}, \mathrm{C}, \mathrm{D}, \mathrm{E}, \mathrm{F}$

Helen Egan

$1 \cdot \mathrm{A}, \mathrm{B}, \mathrm{C}, \mathrm{D}, \mathrm{E}, \mathrm{F}$

Craig Jackson

$1 \cdot A, B, E$
Edward Nash

$2 \cdot \mathrm{A}, \mathrm{B}, \mathrm{E}$

Anna Regan

$2 \cdot \mathrm{A}, \mathrm{B}, \mathrm{E}$

Michail Mantzios

$1 \cdot A, B, C, D, E, F$

\title{
A weekend/weekday comparison of adherence to daily treatment regimens in adults with cystic fibrosis
}

\begin{abstract}
BACKGROUND
Treatment adherence is a major concern in cystic fibrosis (CF), with accumulating evidence that health outcomes are worse in patients with lower levels of adherence. This study investigates how adherence differs for adults with CF during a weekday and a weekend day by examining the roles of sex, anxiety, depression, and lung function as predictors of adherence.
\end{abstract}

\section{PARTICIPANTS AND PROCEDURE}

Fifty-two adult participants with CF were recruited. Demographics and spirometry results were recorded. Participants completed the Hospital Anxiety and Depression Scale and two daily phone diaries in order to record their adherence to pancreatic enzymes, vitamins, physiotherapy and exercise. Based on previous findings, it was hypothesised that reported adherence would be higher during the weekend in comparison to weekdays, due to lower time pressure during the weekend.

\section{RESULTS}

Paired sample $t$-tests indicated that overall participants had higher reported adherence during the weekend in comparison to weekdays, with sex, anxiety, depression and lung function being predictors of adherence.

\section{CONCLUSIONS}

Clinical implications and future directions are discussed, with an emphasis on the need for further qualitative research. We are now conducting another research project utilising qualitative interviews with participants to further investigate adherence within the CF population. Our aim is to identify the main adherence barriers and to develop interventions to improve treatment adherence in the $\mathrm{CF}$ population.

\section{KEY WORDS}

cystic fibrosis; adults; daily treatments; adherence; daily phone diary

ORGANISATION - 1: Birmingham City University, Birmingham, UK · 2: West Midlands Adult Cystic Fibrosis Centre, Heart of England NHS Foundation Trust, Birmingham, UK

AUthors' Contributions - A: Study design - B: Data collection - C: Statistical analysis - D: Data interpretation .

E: Manuscript preparation · F: Literature search · G: Funds collection

Corresponding AUthor - Rebecca Keyte, Department of Psychology, School of Social Sciences, Birmingham City University, The Curzon Building, 4 Cardigan Str., B4 7BD Birmingham, United Kingdom,

e-mail: Rebecca.Keyte@mail.bcu.ac.uk

to Cite this ARTICLE - Keyte, R., Egan, H., Jackson, C., Nash, E., Regan, A., \& Mantzios, M. (2018). A weekend/weekday comparison in adherence to daily treatment regimens for adults with cystic fibrosis. Health Psychology Report, 6(2), 146-157. doi: https://doi.org/10.5114/hpr.2018.72331

RECEIVED 30.06.2017 · REVIEWED 08.08.2017 • ACCEPTED 23.09.2017 • PUBLISHED 18.12.2017 


\section{BACKGROUND}

The increased life expectancy for people with $\mathrm{CF}$ is creating a welcome challenge for health care professionals in supporting adolescent patients as they become increasingly responsible for their own medical regimens (Bregnballe, Schiotz, Boisen, Pressler, \& Thastum, 2011). The challenges for CF patients are manifold in independently maintaining their complex and time-consuming daily treatment regimens, involving medication (e.g. pancreatic enzymes, vitamins), physiotherapy and exercise (Barker, Driscoll, Modi, Light, \& Quittner, 2012). Ongoing treatment adherence is a major concern within the CF population (Horne, 2000); with Eakin, Bilderback, Boyle, Mogayzel, and Riekert (2011), demonstrating that poor adherence is a significant predictor of pulmonary exacerbations during a 12 -month period. Furthermore, Quittner et al. (2014) indicated through the use of medication progression ratios how adherence to long-term pulmonary medications are significant predictors of subsequent health-care use and costs, with poor adherence being associated with acute health-care. Therefore effort needs to be made to improve treatment adherence within the CF population, by creating an intervention for clinicians to implement to promote adherence, thus improving subsequent health outcomes (Eakin et al., 2011). In order to create such an intervention, factors associated with adherence need to be more clearly identified.

Research evidence indicates that adherence within CF differs between treatment types, with adherence to physiotherapy and vitamins being lower than adherence to pancreatic enzymes and exercise (Abbott, Dodd, Bilton, \& Webb, 1994). Abbott et al. (1994) suggest that this may be because patients prioritise short-term treatment benefits, with less consideration for long-term benefits. This previous research did not investigate adherence to inhaled therapies (e.g. mucolytics and antibiotics), but it is important to recognise that many patients view inhaled therapies as being distinct from physiotherapy.

There are a number of factors that have been identified in the literature as having an impact on adherence success. Limited positive reinforcement, as health may deteriorate despite adherence efforts (Kettler et al., 2002), the challenge of fitting complex regimens into daily routine (Horne, Weinman, Barber, Elliot, \& Morgan, 2006), and time pressures have been identified as relevant determinants of adherence.

Much of the focus in research has been around time pressures. McNamara, McCormack, McDonald, Heaf, and Southern (2009) demonstrated that children with $\mathrm{CF}$ are more adherent to nebulised therapies in the evenings in comparison to the mornings, suggesting greater time pressures in the mornings (for both parents and children) (Latchford, Duff, Quinn, Conway,
\& Conner, 2009; McNamara et al., 2009). This is supported by Bregnballe et al.'s work (2011), with $60.00 \%$ of $\mathrm{CF}$ adolescents agreeing that one of the main adherence barriers is a lack of time. Ball et al. (2013) examined weekday/weekend and term-time/holiday adherence to nebulised therapies in adolescents with $\mathrm{CF}$ over an academic year. Within this research adherence was shown to be higher during weekdays in comparison to weekends, and during term times in comparison to holidays, demonstrating the importance of integrating CF care into "structured, daily family schedules, which act to contain treatments" (Horne et al., 2006). Ball et al.'s (2013) findings may not be replicated in an adult CF population, as there may be discrepancies between the time pressures experienced by adult and paediatric patients.

Research investigating adherence within CF has identified the roles of anxiety, depression and disease severity as predictors of adherence. Kettler et al. (2002) suggest that an increase in disease severity may be associated with a decrease in adherence. However, Abbott et al. (1994) found no association between disease severity and adherence in an earlier study, and this was confirmed by Daniels et al. (2011) using electronic monitoring data. A concomitant increase in psychological distress may also account for a reduction in adherence (Kilbourne, 2005; Sundbom \& Bingefors, 2013). Hillard, Eakin, Borrelli, Green, and Riekert (2014) concluded that higher depressive symptoms within CF patients are associated with less positive medication beliefs, which is associated with lower medication adherence, demonstrating the need to monitor depressive symptoms within CF patients to help identify risks for non-adherence. In contrast, research has suggested that people with $\mathrm{CF}$ who have concerns and anxieties about their health are motivated to adhere to their treatments, with such concerns surrounding CF's life-threatening status, and the uncertain future this brings, with some people describing how health deterioration can exacerbate their concerns (Keyte et al., 2017). Backström-Eriksson, Sorjonen, Bergsten-Brucefors, Hjelte, and Melin (2015) suggested that there is no elevated risk for anxiety or depression amongst CF patients.

Sex differences in adherence have also been demonstrated to be important within the CF population (Abbott, Havermans, \& Hart, 2009), with female adolescents with CF displaying more non-adherent behaviours and attitudes than male adolescents with CF (Patterson, Wall, Berge, \& Milla, 2008). These differences were most evident for behaviours that were visible to peers (embarrassment about coughing, skipping medications), which could contribute to self-consciousness (Patterson et al., 2008).

Despite advances in the understanding of factors that potentially predict adherence, adherence within $\mathrm{CF}$ is still poorly understood. Adherence rates vary across studies, due to the variety of different
Weekend/weekday daily treatment adherence in adults with cystic fibrosis 
Rebecca Keyte, Helen Egan, Craig Jackson, Edward Nash, Anna Regan, Michail Mantzios methodologies used and the limitations of these methodologies (Kettler et al., 2002). As self-reported measures often inflate rates of adherence, there is a need to investigate methodologies that are accurate and reliable (Modi et al., 2006; O'Donohoe \& Fullen, 2014). Electronic data collection methods, for instance nebulisers which directly record adherence to nebulised treatment (Daniels et al., 2011), are the "gold standard", but this technology cannot currently be used to assess adherence to tablet treatments and chest physiotherapy. One methodology which attempts to address some of these limitations is the Daily Phone Diary (DPD). Modi et al. (2006) found that DPDs did not inflate rates of adherence (in contrast to self-report measures), and that the DPD methodology provides a more objective measure of adherence for certain treatment modalities, in comparison to self-report measures. Several adherence studies have utilised DPDs, with researchers concluding that this method demonstrates good reliability and validity when recording adherence within CF (Modi \& Quittner, 2006; Quittner \& Espelage, 1999).

This study aimed to investigate how adherence to pancreatic enzymes, vitamins, physiotherapy and exercise differs for $\mathrm{CF}$ adults during a weekday and a weekend day by examining the roles of sex, anxiety, depression, and lung function as predictors of adherence. Adherence was measured utilising the DPD methodology. It was hypothesised that reported adherence would be higher during the weekend in comparison to weekdays, due to it being expected that the time pressures are less for adults during the weekend (Bregnballe et al., 2011; McNamara et al., 2009; Latchford et al., 2009).

\section{PARTICIPANTS AND PROCEDURE}

\section{STUDY DESIGN}

A within-participants design was utilised to compare the adherence of individuals with CF during the weekend in comparison to weekdays.

\section{RECRUITMENT}

Fifty-two participants (27 females, 25 males), who were all adult patients aged 18-54 years $(M=29.59$ years, $S D=10.01$ ) were recruited at the West Midlands Adult Cystic Fibrosis Centre. Eligibility criteria included: 1) having the capacity to decide upon one's participation (identified by the patient's consultant) 2) being an outpatient 3) English speaking. Opportunity sampling was utilised by inviting patients attending clinics to participate in this study. In total, 71 patients were approached and invited to participate; 19 patients refused participation. Patients gave a variety of reasons for not participating, which included time restrictions, negative affect and phone calls not being suitable. Once informed consent had been established, participants completed the Hospital Anxiety and Depression Scale (HADS) (Sundbom \& Bingefors, 2013) during clinic time. The participant was then contacted on two days (one weekend day and one weekday within the next week) via telephone by the researcher, recording the number of treatments performed (physiotherapy, pancreatic enzymes, vitamins and exercise), in comparison to the number of prescribed treatments, to collect their adherence percentage.

\section{THE HOSPITAL ANXIETY AND DEPRESSION SCALE}

The HADS (Zigmond \& Snaith, 1983) is a well-established and well-validated screening tool, which is short and easy to administer (Backström-Eriksson et al., 2015). It is a fourteen item questionnaire which measures symptoms of emotional distress whilst excluding symptoms which would have derived from a physical disorder (Backström-Eriksson et al., 2015). The questionnaire has two separate scales, one assessing for anxiety, the other assessing for depression, with both scales having good psychometric properties (mean Cronbach's $\alpha$ for the anxiety subscale was .83 and for the depression subscale was .82) (Bjelland, Dahl, Haug, \& Neckelmann, 2002). The anxiety and depression scales each have seven questions. Participants have to indicate the extent to which they do or do not perform that task, or feel how described in each statement on a four-point Likert scale, which ranges from 0 (not at all) to 3 (most of the time). Scores for each scale are categorised as normal (0-7), mild (8-10), moderate (11-14) and severe (15-21) (Snaith \& Zigmond, 2012). In order to analyse the data a median split was used to separate the groups into "high levels of anxiety", "low levels of anxiety", and "high levels of depression", "low levels of depression".

\section{DAILY PHONE DIARY}

The DPD methodology uses a day reconstruction method (Kahneman, Krueger, Schkade, Schwarz, \& Stone, 2004) attempting to reduce memory and recall issues which are associated with questionnaires (Modi \& Quittner, 2006). The cued recall procedure used within this method (asking participants to report all activities that have occurred within the past twenty-four hours) is believed to result in an increase in participants reporting actual behaviours, rather than estimates (Modi et al., 2006). Previous research has shown that the DPD methodology reduces the occurrence of memory decay and decreases the likelihood of social desirability bias, as it is difficult 
for participants to report an activity which did not happen when they are tracked through twenty-four hours (Quittner, Modi, Lemanek, Ievers-Landis, \& Rapoff, 2008). Quittner, DiGirolamo, Michel, and Eigen (1992) reported that within a CF population the DPD methodology "yielded reliable stability coefficients over a three week period ( $r$ values $=.61-.71$, $p=.010)$ along with high levels of inter-rater reliability (> 90.00\%)" (Modi \& Quittner, 2006, p. 6). DPDs can also identify barriers to adherence, due to participants recording all activities they have engaged in, not just their medical regimens (Quittner et al., 2008). Finally, it is reported that DPDs are an unobtrusive adherence measure, with patients often forgetting that medical regimens are the focus of the report, as all activities during a twenty-four hour period are recorded (Modi et al., 2006).

The DPDs (Modi et al., 2006) were used to collect data on participants' adherence to their medical regimens. Cystic fibrosis daily medical regimens vary amongst patients; therefore the researcher reordered each participant's prescribed daily regimens for pancreatic enzymes, vitamins, chest physiotherapy and exercise (see Table 1). The researcher utilised patients' hospital records for the description of what was prescribed or recommended by their clinicians for each of the four treatment types. Despite CF patients having to adhere to a range of other important treatments, this research only investigated adherence to the four treatment types investigated by Abbott et al. (1994) in order to emulate this research using a DPD rather than questionnaires to measure adherence. The DPDs tracked participants through the activities they engaged in over the past twenty-four hours to record their adherence to pancreatic enzymes, vitamins, physiotherapy and exercise, by using a day reconstruction method (Kahneman et al., 2004), accompanied by a cued recall procedure. The phone calls were initiated by the researcher, who assisted the participant in accurately reconstructing their day by providing prompts (Modi et al., 2006) (see Table 2). Each activity was recorded by the researcher on a computer, using Windows FileMaker, indicating a twenty-four hour day. Participants completed two DPDs (one weekday and one weekend day with a maximum five-day interval between DPDs), each requiring a maximum of twenty minutes to complete. It was not expected that participants would experience a sick period during these two time periods due to being recruited at their $\mathrm{CF}$ outpatient appointment after their health status had been assessed. The aims of the research were not disclosed to participants, so they were not aware that the research was comparing weekday and weekend adherence; however, they were aware that the research was investigating rates of adherence amongst CF patients. An adherence percentage was calculated for each participant to illustrate their overall adherence, and their adherence to each medical regimen (see Table 3). Due to adherence within CF being predominantly patient led, it was possible for adherence percentages to be above $100.00 \%$, indicating that patients had engaged in that medical regimen more than recommended; it was only expected that this would happen for physiotherapy (in response to health deteriorations), and exercise.

Table 1

Example of the prescribed daily treatments for three participants. This table was created for each participant by a medical record review

\begin{tabular}{|c|c|c|c|c|}
\hline Participant & Pancreatic Enzymes & Vitamins & Physiotherapy & Exercise \\
\hline 1 & $\begin{array}{c}\text { Breakfast tablets: } 6 \\
\text { Lunch tablets: } 8 \\
\text { Dinner tablets: } 12 \\
\text { Snack tablets: } 5\end{array}$ & 7 & $\begin{array}{c}10 \text { minutes twice } \\
\text { a day }\end{array}$ & 60 minutes \\
\hline 2 & $\begin{array}{c}\text { Breakfast tablets: } 8 \\
\text { Lunch tablets: } 9 \\
\text { Dinner tablets: } 10 \\
\text { Snack tablets: } 6\end{array}$ & 3 & $\begin{array}{c}15 \text { minutes twice } \\
\text { a day }\end{array}$ & 60 minutes \\
\hline 3 & $\begin{array}{c}\text { Breakfast tablets: } 3 \\
\text { Lunch tablets: } 5 \\
\text { Dinner tablets: } 7 \\
\text { Snack tablets: } 5\end{array}$ & 3 & $\begin{array}{c}15 \text { minutes twice } \\
\text { a day }\end{array}$ & 30 minutes \\
\hline \multicolumn{5}{|c|}{$\begin{array}{l}\text { Note. Pancreatic enzymes: Required by CF patients who are pancreatic insufficient to aid with digestion; patients are required to } \\
\text { take these prior to eating. Vitamins: Typically vitamins } \mathrm{A}, \mathrm{D}, \mathrm{E} \text { and } \mathrm{K} \text { are required due to the likely malabsorption of fat soluble } \\
\text { vitamins in CF patients, particularly those who are pancreatic insufficient. Physiotherapy: Required by CF patients in order to } \\
\text { reduce the risk of infection and lung damage by preventing thick, sticky mucus in the lungs blocking the airways. Exercise: Re- } \\
\text { quired to assist in the clearance of mucus from the lungs in CF patients and to improve physical bulk and strength. }\end{array}$} \\
\hline
\end{tabular}


Table 2

Sample Daily Phone Diary Schedule in accordance with guidance from Modi et al. (2006)

Sample DPD Interview Schedule

Interviewer: Hello, am I speaking to (Participant number)?

Reply

Interviewer: Thank you, this is Rebecca Keyte, we met at (name of hospital) on (date). Would this be a good time for us to complete the phone diary as agreed?

Reply

Interviewer: Thank you. I would like you to report all activities you have engaged in during the past

Rebecca Keyte,

Helen Egan,

Craig Jackson,

Edward Nash,

Anna Regan,

Michail Mantzios

24 hours. So what time did you wake up yesterday morning?

Reply

- For the remainder of the interview prompts will be used to remind the participant of what activities they engaged in.

- After any mention of food/meals the interviewer will ask: "And how many pancreatic enzymes did you take with that?"

- If there is no mention of vitamins, at the end of the interview the interviewer will say "Have you taken any vitamin tablets during the past twenty-four hours?" Reply; Interviewer "And how many of these tablets did you take?"

END:

Interviewer: Thank you for your time to complete this phone diary. The information you have disclosed to me is clear; I have no further questions to ask you. Are there any questions you would like to ask me?

Table 3

How participants' adherence percentages were calculated

How to record adherence percentages (Modi et al., 2006)

Number of treatments performed that day/number prescribed X $100=\%$ adherence for that day

Overall adherence $\%=$ (physiotherapy $\%$ adherence + exercise $\%$ adherence + pancreatic enzymes $\%$ adherence + vitamins $\%$ adherence) $/ 4$

\section{MEDICAL RECORDS}

Medical records were used to record participants' demographics, most recent spirometry result (forced expiratory volume in one second as percentage of predicted, $\mathrm{FEV}_{1} \%$ predicted), comorbidities and medications. In order to analyse the data indicating disease severity a median split was used to separate the groups into "high lung function" and "low lung function”. Participants' lung function was recorded by their health care professionals as part of their clinic appointment to provide an indication of their pulmonary function.

\section{STATISTICAL ANALYSIS}

Due to the small sample size, paired-sample $t$-tests were carried out using SPSS 21.0 for Windows.

\section{ETHICAL APPROVAL}

All procedures performed within this research was in accordance with the ethical standards of the national research committee. Ethical approval was granted by NRES Committee East Midlands - Derby. Informed consent was obtained from all individual participants included in the study.

\section{RESULTS}

\section{DESCRIPTIVE STATISTICS}

Participants reported adhering most to exercise, followed by pancreatic enzymes, vitamins, and physiotherapy. The majority of participants did not show evidence of anxiety or depression $(0-7=$ normal $)$ (see Table 4$)$.

\section{WEEKEND/WEEKDAY COMPARISON IN ADHERENCE}

There was a significant difference in the scores for the weekday physiotherapy and the weekend physiotherapy conditions, with participants having higher reported adherence to physiotherapy during the weekend in comparison to weekdays. Adherence to weekend exercise was also reported to be signifi- 
cantly higher than weekday exercise. There was no significant difference between weekday and weekend adherence to pancreatic enzymes and vitamins, but when combining all of the data, there was overall better adherence to treatments on weekend days compared to weekdays (see Table 5).

Multivariate ANOVA revealed a statistically significant different in adherence to exercise during the weekdays in comparison to adherence during the weekend, $F(92,90)=2.02, p<.001$; Wilks' $\Lambda=.012$, partial $\eta^{2}=.67$. Analysis of each individual dependent variable, using a Bonferroni adjusted $\alpha$ level of .02, showed that there was a significant difference for anxiety $F(23,25)=2.47, p=.015$, partial $\eta^{2}=.69$, and for depression $F(23,25)=2.43, p=.016$, partial $\eta^{2}=.69$.

\section{SEX DIFFERENCES BETWEEN CYSTIC FIBROSIS PATIENTS' ADHERENCE}

There was a significant difference for female participants in the scores for the weekday exercise and the weekend exercise conditions, with female participants having higher reported adherence to exercise during the weekend in comparison to weekdays. There was no significant difference between weekday and weekend adherence to physiotherapy, pancreatic enzymes or vitamins for females with CF, but when combining all of the data for female participants, there was overall better adherence to treatments on weekend days compared to weekdays (see Table 6). In addition, when combining all of the data for male participants, there was no overall difference in adherence to treatments during the weekend in comparison to weekdays (see Table 6).

\section{ANXIETY AND ADHERENCE}

There was a significant difference for participants with low levels of anxiety in the scores for the weekday vitamin and weekend vitamin conditions, with participants having higher reported adherence to vi-
Table 4

Descriptive statistics

\begin{tabular}{lc}
\hline Measurements & $M(S D)$ \\
\hline Age & $29.59(10.00)$ \\
Anxiety (HAD-A) & $5.82(3.66)$ \\
Depression (HAD-D) & $3.39(3.63)$ \\
Lung function (FeV1) & $56.49 \%(23.84)$ \\
$\begin{array}{l}\text { Overall exercise adherence } \\
\text { Overall pancreatic enzyme }\end{array}$ & $97.30 \%(106.43)$ \\
$\begin{array}{l}\text { adherence } \\
\text { Overall vitamin adherence }\end{array}$ & $83.80 \%(17.93)$ \\
$\begin{array}{l}\text { Overall physiotherapy } \\
\text { adherence }\end{array}$ & $58.37 \%(33.02)$ \\
\hline
\end{tabular}

tamins during the weekdays in comparison to weekends. There was no significant difference between weekday and weekend adherence to physiotherapy, exercise or pancreatic enzymes for participants with low levels of anxiety (see Table 7). In addition, there was a significant difference for participants with high levels of anxiety in the scores for the weekday exercise and weekend exercise conditions, with participants having higher reported adherence to exercise during the weekend in comparison to weekdays. There was no significant difference between weekday and weekend adherence to physiotherapy, pancreatic enzymes or vitamins for participants with high levels of anxiety, but when combining all of the data for participants with high levels of anxiety, there was overall better adherence to treatments at weekends compared to weekdays (see Table 7).

\section{DEPRESSION AND ADHERENCE}

There was a significant difference for participants with high levels of depression in the scores for the
Weekend/weekday daily treatment adherence in adults with cystic fibrosis

\section{Table 5}

Mean scores and standard deviations as well as mean comparisons for overall adherence during the weekend in comparison to weekdays

\begin{tabular}{|c|c|c|c|c|c|}
\hline \multicolumn{6}{|c|}{ Weekend/weekday comparison in adherence } \\
\hline \multirow[t]{2}{*}{ Treatment } & \multicolumn{2}{|c|}{$M(S D)$} & \multirow[t]{2}{*}{$t$} & \multirow[t]{2}{*}{$p$} & \multirow[t]{2}{*}{$\eta^{2}$} \\
\hline & Weekday & Weekend & & & \\
\hline Physiotherapy & $50.38(51.74)$ & $67.40(85.71)$ & -2.42 & .019 & .11 \\
\hline Exercise & $69.42(104.95)$ & 125.17 (152.49) & -2.56 & .014 & .12 \\
\hline Pancreatic enzyme & $93.28(19.23)$ & $94.32(17.42)$ & -0.95 & .349 & - \\
\hline Vitamin & $89.41(36.77)$ & $80.66(39.84)$ & 1.56 & .124 & - \\
\hline Overall & $75.62(28.37)$ & $89.85(45.06)$ & -2.19 & .034 & .09 \\
\hline
\end{tabular}


weekday physiotherapy and weekend physiotherapy conditions, with participants having higher reported adherence to physiotherapy during the weekend in comparison to weekdays. There was no significant difference between weekday and weekend adherence to exercise, pancreatic enzymes or vitamins for participants with high levels of depression, but when combining all of the data for participants with high levels of depression, there was overall better adher- ence to treatments at weekends compared to weekdays (see Table 8).

\section{$\mathrm{FEV}_{1}$ AND ADHERENCE}

There was a significant difference for participants with a low lung function in the scores for the weekday exercise and weekend exercise con-
Rebecca Keyte, Helen Egan, Craig Jackson, Edward Nash, Anna Regan, Michail Mantzios

Table 6

Mean scores and standard deviations as well as mean comparisons in overall adherence by sex

\begin{tabular}{lccccc}
\hline \multicolumn{2}{l}{ Weekend/Weekday comparison in adherence by sex } & & & \\
\hline \multicolumn{1}{l}{ Treatment } & Weekday & Weekend & $t$ & $p$ & $\eta^{2}$ \\
\hline Females & & & & \\
Physiotherapy & $62.32(59.32)$ & $82.70(109.12)$ & -1.68 & .107 & - \\
Exercise & $59.58(70.16)$ & $122.92(125.76)$ & -2.59 & .016 & .23 \\
Pancreatic enzyme & $93.86(16.21)$ & $96.22(9.45)$ & -1.17 & .255 & - \\
Vitamin & $85.85(28.10)$ & $79.81(37.85)$ & 0.68 & .505 & - \\
Overall & $75.41(22.08)$ & $95.41(43.15)$ & -2.90 & .008 & .27 \\
Males & & & & .12 \\
Physiotherapy & $38.91(41.25)$ & $52.71(53.13)$ & -1.82 & .082 & - \\
Exercise & $78.87(130.86)$ & $127.33(177.03)$ & -1.34 & .192 & - \\
Pancreatic enzyme & $92.72(22.07)$ & $92.51(22.67)$ & 0.22 & .829 & - \\
Vitamin & $92.83(43.85)$ & $81.47(42.43)$ & 1.63 & .117 & .435 \\
Overall & $75.83(33.79)$ & $84.51(47.08)$ & -0.79 & .45 & -
\end{tabular}

Table 7

Mean scores and standard deviations as well as mean comparisons in overall adherence by levels of anxiety

\begin{tabular}{lccccc}
\hline Anxiety and adherence & & & & \\
\hline Treatment & Weekday & Weekend & $t$ & $p$ & $\eta^{2}$ \\
\hline Low level anxiety & & & & & \\
Physiotherapy & $50.66(52.73)$ & $71.56(94.16)$ & -1.91 & .070 & .14 \\
Exercise & $75.58(130.86)$ & $125.36(186.33)$ & -1.30 & .207 & - \\
Pancreatic enzyme & $90.58(24.53)$ & $89.73(24.05)$ & 0.70 & .490 & - \\
Vitamin & $102.64(34.16)$ & $83.12(40.37)$ & 2.43 & .024 & .21 \\
Overall & $79.87(34.36)$ & $88.09(55.59)$ & -0.66 & .515 & - \\
High level anxiety & & & & .153 & - \\
Physiotherapy & $50.13(51.88)$ & $63.72(79.20)$ & -1.48 & .21 \\
Exercise & $63.97(77.55)$ & $125.00(118.72)$ & -2.55 & .017 & - \\
Pancreatic enzyme & $95.67(12.96)$ & $98.39(6.09)$ & -1.56 & .131 & - \\
Vitamin & $77.71(35.58)$ & $78.48(40.04)$ & -0.10 & .918 & .33 \\
Overall & $71.87(21.78)$ & $91.40(34.27)$ & -3.53 & .002 & \\
\hline
\end{tabular}


ditions, with participants having higher reported adherence to exercise on weekend days compared to weekdays. There was no significant difference between weekday and weekend adherence to physiotherapy, pancreatic enzymes or vitamins for participants with a low lung function, but when combining all of the data for participants with a low lung function, there was overall better adherence to treatments on weekend days compared to weekdays (see Table 9).

Table 8

Mean scores and standard deviations as well as mean comparisons in overall adherence by levels of depression

\begin{tabular}{|c|c|c|c|c|c|}
\hline \multicolumn{6}{|c|}{ Depression and adherence } \\
\hline Treatment & Weekday & Weekend & $t$ & $p$ & $\eta^{2}$ \\
\hline \multicolumn{6}{|l|}{ High level depression } \\
\hline Physiotherapy & $47.79(53.07)$ & $73.30(89.36)$ & -2.29 & .032 & .19 \\
\hline Exercise & $69.78(105.22)$ & $123.91(126.51)$ & -1.91 & .069 & - \\
\hline Pancreatic enzyme & $95.72(13.59)$ & $97.56(6.94)$ & -0.90 & .377 & - \\
\hline Vitamin & $81.84(33.19)$ & $78.41(42.61)$ & 0.48 & .638 & - \\
\hline Overall & $73.78(27.98)$ & $93.29(34.85)$ & -2.82 & .010 & .27 \\
\hline \multicolumn{6}{|l|}{ Low level depression } \\
\hline Physiotherapy & $52.67(51.47)$ & $62.18(83.77)$ & -1.08 & .291 & - \\
\hline Exercise & $69.10(106.80)$ & $125.28(174.81)$ & -1.73 & .096 & - \\
\hline Pancreatic enzyme & $91.12(23.18)$ & $91.46(22.84)$ & -0.32 & .750 & - \\
\hline Vitamin & $96.11(39.08)$ & $82.65(37.96)$ & 1.60 & .123 & - \\
\hline Overall & 77.25 (29.15) & $86.80(53.01)$ & -0.89 & .380 & - \\
\hline
\end{tabular}

Table 9

Mean scores and standard deviations as well as mean comparisons in overall adherence by disease severity

\begin{tabular}{|c|c|c|c|c|c|}
\hline \multicolumn{6}{|c|}{ Lung function $\left(\mathrm{FEV}_{1}\right)$ and adherence } \\
\hline Treatment & Weekday & Weekend & $t$ & $p$ & $\eta^{2}$ \\
\hline \multicolumn{6}{|l|}{ Low lung function } \\
\hline Physiotherapy & $68.45(58.15)$ & 89.95 (104.51) & -1.84 & .078 & - \\
\hline Exercise & $43.78(55.99)$ & $102.56(89.40)$ & -3.08 & .005 & .27 \\
\hline Pancreatic enzyme & $94.78(19.95)$ & $96.15(19.61)$ & -1.41 & .170 & - \\
\hline Vitamin & $83.10(42.67)$ & $76.68(44.49)$ & 0.75 & .463 & - \\
\hline Overall & $72.53(22.60)$ & $91.34(38.56)$ & -3.34 & .003 & .31 \\
\hline \multicolumn{6}{|l|}{ High lung function } \\
\hline Physiotherapy & $29.95(34.29)$ & $41.91(48.34)$ & -1.66 & .111 & - \\
\hline Exercise & $98.41(137.17)$ & $150.72(200.91)$ & -1.26 & .222 & - \\
\hline Pancreatic enzyme & $91.58(18.67)$ & $92.23(14.71)$ & -0.32 & .753 & - \\
\hline Vitamin & $96.55(27.93)$ & $85.14(34.26)$ & 1.61 & .121 & - \\
\hline Overall & $79.12(33.92)$ & $88.16(52.30)$ & -0.73 & .474 & - \\
\hline
\end{tabular}

Weekend/weekday daily treatment adherence in adults with cystic fibrosis 
Rebecca Keyte, Helen Egan, Craig Jackson, Edward Nash, Anna Regan, Michail Mantzios sex, anxiety, depression and lung function being predictors of adherence. This research therefore supports previous work in indicating that an increase in disease severity has an impact on adherence within CF patients (Kettler et al., 2002), as does the occurrence of anxiety and/or depression (Hillard et al., 2014).

In the current research, overall adherence rates were higher than expected $(83.80 \%)$ in comparison to previous research which has documented that adherence within $\mathrm{CF}$ varies in the range $50.00-70.00 \%$ (Abbott et al., 1994; McNamara et al., 2009). However, the overall adherence in the current research could have been influenced by social desirability bias, which if present would have inflated participants' rates of adherence. For instance, the interview approach involved the use of prompts; in particular, if a participant did not mention adherence to vitamin treatments, the researcher would specifically ask whether any vitamins were taken during that day, rather than assuming non-adherence based on the lack of report.

In line with previous research, the results of the current research indicate that adherence differs between treatment types (Abbott et al., 1994; O'Donohoe et al., 2014). However, in the current research adherence was highest for pancreatic enzymes and vitamins, whereas Abbott et al. (1994) reported that adherence was highest for pancreatic enzymes and exercise. Abbott et al. (1994) hypothesised that adherence was influenced by the short-term benefits of treatment. However, the results from the current research indicate that a patient's adherence may be influenced by the time it takes to complete a particular treatment, with physiotherapy and exercise requiring more time from a patient than pancreatic enzyme and vitamin treatments.

The results of the current research differ from those of Ball et al. (2013), who found that reported adherence in a cohort of paediatric CF patients was significantly higher on weekdays compared to weekends. Due to the current research using a different method to Ball et al. (2013) in order to record rates of adherence, this difference in findings provides a suggestion for future research, to investigate the adherence relationship between paediatric and adult CF patients using the same method, whether that is the DPD methodology or an objective time and date stamped nebuliser.

It is plausible that adult patients experience difficulty adhering to treatments during the weekdays due to patients experiencing an increase in responsibility for their own medical regimens as they enter adulthood, with parents/guardians no longer having as much control of their treatments. This may result in $\mathrm{CF}$ patients finding it more challenging to independently integrate their daily treatments within their weekday lifestyle alongside other life commitments. Bregnballe et al. (2011) support this assertion, indicating that one of the main adherence barriers is a lack of time.
It may also be the case that $\mathrm{CF}$ adolescents and adults are consciously choosing to be non-adherent during the weekdays in an attempt to hide their illness from their peers. All patients have illness cognitions to provide themselves with a framework for coping and understanding their illness (Leventhal, Weinman, Leventhal, \& Phillips, 2007); one cognitive dimension of these beliefs is identity. It is possible that CF patients do not adhere to their medical regimens in front of their peers during the weekdays (e.g. at college/university/work) in order to hide their illness, and this is being further examined by the authors in a follow-up study.

Indeed, an important concept within identity is image, with Yates et al. (2010) suggesting that many chronically ill individuals favour a degree of invisibility towards their illness, allowing them greater normalcy. In terms of CF, patients can often appear to be "physically normal" as CF is a relatively invisible impairment (Tierney, 2012). However, patients may feel that their illness is on display when they have to engage in medical regimens (e.g. taking tablets in public), and therefore some CF patients may consciously choose to be non-adherent to uphold this sense of invisibility (Withers, 2012). Bregnballe et al. (2001) indicated that one of the main adherence barriers in $\mathrm{CF}$ is unwillingness to take medications in public.

The role of identity could explain why the weekend/weekday difference in adherence was most prevalent in adult female CF patients. Patterson et al. (2008) demonstrated that female adolescents with CF display more non-adherent behaviours in comparison to male adolescents with CF. In particular, females were more likely to experience embarrassment when coughing and taking CF medications. Therefore female CF patients may have lower reported adherence during the weekdays due to their conscious efforts to avoid following their medical regimens in front of their peers (at college/university/work), in order to provide themselves with a normal identity that does not highlight their CF. Further research which demonstrates that female CF patients prefer a sense of invisibility to their illness comes from Higham et al. (2013). They found that in order to be perceived as normal, many female CF patients hide their illness from their partners, with the majority of female CF patients only disclosing their illness to their partner when they believe their relationship is going to be long-term.

Interestingly, this research found DPDs to be an effective technique in highlighting adherence barriers. These barriers were not recorded in the results of the present study due to this study following a positivist approach; however, these barriers provide a rationale for adherence within $\mathrm{CF}$ to be investigated using qualitative measures, to provide an in-depth insight into barriers and enablers to adherence with- 
in the CF population. For example, one participant disclosed that they were concerned that they were always prescribed the same antibiotics, and they were concerned that their antibiotics were no longer effective. This participant had contacted "Facebook groups" in which CF patients were voicing their concerns that the limited range of antibiotics available to them was resulting in the antibiotics no longer being as effective in treating their lung disease. As patients have become more active in seeking information regarding antibiotic use outside of clinical advice (Harris, Sillence, \& Briggs, 2011; Scanfeld, Scanfeld, \& Larson, 2010) the increasing life expectancy in CF is creating new challenges in successively treating the disease. Patients' concerns may also be exacerbated due to campaigns in the United Kingdom surrounding antibiotic safety. Qualitative research could usefully investigate the impact such campaigns have on people with long-term conditions.

Several limitations of this study are acknowledged, each of which suggests important future directions. First, the small sample size was problematic, as it restricted the analyses that could project a high power. In addition, while the researchers acknowledge the methodological limitations of dichotomization and are aware that methodological literature favours the use of regressional methods on undichotomized variables (MacCallum, Zhang, Preacher, \& Rucker, 2002), the latest research indicates that potential loss of information or the possibility of a type I error (MacCallum et al., 2002) is not always true. In fact, Iacobucci et al. (2015) suggested that there could be analytical integrity to dichotomized variables, and that the parsimonious nature of median splits may well be a preferred option. While the arguments and critiques still continue in the field of dichotomising continuous variables (Rucker, McShane, \& Preacher, 2015), and data continue to emerge with the main analyses centring on dichotomized variables, we suggest that future research with larger sample sizes from multiple CF sites are required to support current findings.

Other potential limitations may relate to the underestimation of how many CF patients experience psychological distress (in particular depression), as some research indicates that the HADS is potentially insensitive as it does not detect as many cases of depression as the Patient Health Questionnaire (PHQ-9) (Hansson, Nordstom, \& Bodlund, 2009). The researcher did not have any prior knowledge regarding participants' psychological health. Whilst it is acknowledged that individuals suffering from depression are less likely to participate in research, only three out of the nineteen patients who refused participation explained that this was due to a negative affect. Also, the time pressure was taken as given, based on previous findings, but may well relate to other psychosocial factors such as employment status and other family commitments (e.g., Taylor-Rob- inson, Smyth, Diggle, \& Whitehead, 2013), which should be explored in future research. In addition, whilst this research aimed to emulate that of Abbott et al. (1994) in investigating how adherence differs between pancreatic enzymes, vitamins, physiotherapy and exercise, the fact that this research did not investigate adherence to respiratory medications is a limitation, with further research being required to investigate how adherence to respiratory medications varies during the weekend and weekdays.

To advance the current research and investigate more fully the changes in adherence patterns during the transition from paediatric to adult care, qualitative research is required. We are therefore in the process of conducting qualitative interviews with $\mathrm{CF}$ patients to investigate the relationship between health beliefs and health behaviours within the CF population, which will increase understanding of why some patients have poor adherence to their medical regimens, especially during the weekdays. Personal identity, levels of acceptance and managing $\mathrm{CF}$ as an adult are some of the themes currently being explored. The results of this research will identify specific personal barriers to adherence and inform interventions aimed at reducing these barriers and improve treatment adherence within the CF population.

\section{References}

Abbott, J., Dodd, M., Bilton, D., \& Webb, A. K. (1994). Treatment compliance in adults with cystic fibrosis. Thorax, 49, 115-120. doi: 10.1136/thx.49.2.115

Abbott, J., Dodd, M., \& Webb, A. K. (1996). Health perceptions and treatment adherence in adults with cystic fibrosis. Thorax, 51, 1233-1238. doi: 10.1136/thx.51.12.1233

Abbott, J., Havermans, T., \& Hart, A. (2009). Adherence to the medical regimen: clinical implications of new findings. Current Opinion in Pulmonary Medicine, 15, 597-603. doi: 10.1097/ MCP.0b013e3283310859

Backström-Eriksson, L., Sorjonen, K., BergstenBrucefors, A., Hjelte, L., \& Melin, B. (2015). Anxiety and depression in adults with cystic fibrosis: a comparison between patients and the general population in Sweden and three other European countries. BioMed Central Pulmonary Medicine, 15, 121. doi: 10.1186/s12890-015-0117-9

Ball, R., Southern, K.W., McCormack, P., Duff, A. J. A., Brownlee, K. G., \& McNamara, P. S. (2013). Adherence to nebulised therapies in adolescents with cystic fibrosis is best on week-days during school term-time. Journal of Cystic Fibrosis, 12, 440-444. doi: 10.1016/j.jcf.2012.12.012

Barker, D. H., Driscoll, K. A., Modi, A. C., Light, M. J., \& Quittner, A. L. (2012). Supporting cystic fibro-
Weekend/weekday daily treatment adherence in adults with cystic fibrosis 
Rebecca Keyte, Helen Egan, Craig Jackson, Edward Nash, Anna Regan, Michail Mantzios sis disease management during adolescence: the role of family and friends. Child: Care, Health and Development, 38, 497-504. doi: 10.1111/j.13652214.2011.01286.x

Bjelland, I., Dahl, A. A., Haug, T. T., \& Neckelmann, D. (2002). The validity of the hospital anxiety and depression scale. An updated literature review. Journal of Psychosomatic Research, 52, 69-77. doi: 10.1016/S0022-3999(01)00296-3

Bregnballe, V., Schiotz, P. O., Boisen, K. A., Pressler, T., \& Thastum, M. (2011). Barriers to adherence in adolescents and young adults with cystic fibrosis: a questionnaire study in young patients and their parents. Patient Preference and Adherence, 5, 507-515. doi: 10.2147/PPA.S25308

Daniels, T., Goodacre, L., Sutton, C., Pollard, K., Conway, S., \& Peckham, D. (2011). Accurate assessment of adherence: self-report and clinician report vs electronic monitoring of nebulizers. Chest, 140, 425-432. doi: 10.1378/chest.09-3074

Eakin, M. N., Bilderback, A., Boyle, M. P., Mogayzel, P. J., \& Riekert, K. A. (2011). Longitudinal association between medication adherence and lung health in people with cystic fibrosis. Jour nal of Cystic Fibrosis, 10, 258-264. doi: 10.1016/j. jcf.2011.03.005

Hansson, M., Nordstom, A., \& Bodlund, O. (2009). Comparison of two self-rating scales to detect depression: HADS and PHQ-9. The British Journal of General Practice, 59, 283-288. doi: 10.3399/ bjgp09X454070

Harris, P. R., Sillence, E., \& Briggs, P. (2011). Perceived threat and corroboration: key factors that improve a predictive model of trust in internet-based health information and advice. Journal of Medical Internet Research, 13, 1-16. doi: 10.2196/jmir.1821

Higham, L., Ahmed, S., \& Ahmed, M. (2013). Hoping to live a "normal" life whilst living with unpredictable health and fear of death: impact of cystic fibrosis on young adults. Journal of Genetic Counselling, 22, 374-383. doi: 10.1007/s10897-0129555-1

Hillard, M. E., Eakin, M. N., Borrelli, B., Green, A., \& Riekert, K. A. (2014). Medication beliefs medicate between depressive symptoms and medication adherence in cystic fibrosis. Health Psychology, 34, 496-504. doi: 10.1037/hea0000136

Horne, R. (2000). Assessing perceptions of medications: psychological perspectives. In H. McGavock, Handbook of drug research methodology (pp. 299-319). Newcastle upon Tyne: United Kingdom Drug Utilisation Research Group.

Horne, R., Weinman, J., Barber, N., Elliott, R. A., \& Morgan, M. (2006). Concordance, adherence and compliance in medicine taking: a conceptual map and research priorities. Brighton, UK: National Co-ordinating Centre for NHS Service Delivery and Organisation R\&D. lacobucci, D., Posavac, S. S., Kardes, F. R., Schneider, M. J., \& Popovich, D. L. (2014). Toward a more nuanced understanding of the statistical properties of a median split. Journal of Consumer Psychology, 25, 652-665. doi: 10.1016/j.jcps.2014.12.002

Kahneman, D., Krueger, A. B., Schkade, D. A., Schwarz, N., \& Stone, A. A. (2004). A survey method for characterizing daily life experience: the day reconstruction method. Science, 306, 1776-1780. doi: 10.1126/science. 1103572

Kettler, L. J., Sawyer, S. M., Winefield, H. R., \& Greville, H. W. (2002). Determinants of adherence in adults with cystic fibrosis. An International Journal of Respiratory Medicine; Thorax, 57, 459-464. doi: 10.1136/thorax.57.5.459

Keyte, R., Beswick, L., Rayner, O., Carr, S. B., Bryon, M., \& Medhurst, N. (2017). Self-reported motivators to treatment adherence in adults with cystic fibrosis in the UK. Journal of Cystic Fibrosis, 16, S62. doi: 10.1016/S1569-1993(17)30365-X

Kilbourne, A. M. (2005). Depression linked to inadequate medication adherence. Diabetic Microvascular Complications Today. Retrieved from http://www.diabeticmctoday.com/HtmlPages/ DMC0505/PDFs/DMC_Kilbourne.pdf

Latchford, G., Duff, A., Quinn, J., Conway, S., \& Conner, M. (2009). Adherence to nebulised antibiotics in cystic fibrosis. Journal of Cystic Fibrosis, 75, 141-144. doi: 10.1016/j.pec.2008.08.027

Leventhal, H., Weinman, J., Leventhal, E. A., \& Phillips, L. A. (2007). Health psychology: the search for pathways between behaviour and health. Annual Review of Psychology, 59, 1-29. doi: 10.1146/ annurev.psych.59.103006.093643

MacCallum, R. C., Zhang, S., Preacher, K. J., \& Rucker, D. D. (2002). On the practice of dichotomization of quantitative variables. Psychological Methods, 7, 19-40. doi: 10.1037//1082-989X.7.1.19

McNamara, P. S., McCormack, P., McDonald, A. J., Heaf, L., \& Southern, K. W. (2009). Open adherence monitoring using routine data download from an adaptive aerosol delivery nebuliser in children with cystic fibrosis. Journal of Cystic Fibrosis, 8, 258-263. doi: 10.1016/j.jcf.2009.04.006

Modi, A. C., Lim, C. S., Yu, N., Geller, D., Wagner, M. H., \& Quittner, A. L. (2006). A multi-method assessment of treatment adherence for children with cystic fibrosis. Journal of Cystic Fibrosis, 5, 177185. doi: 10.1016/j.jcf.2006.03.002

Modi, A. C., \& Quittner, A. L. (2006). Utilizing computerized phone diary procedures to assess health behaviours in family and social contexts. Child Health Care, 35, 29-45. doi: 10.1207/s15326888chc3501_4

O’Donohoe, R., \& Fullen, B. M. (2014). Adherence of subjects with cystic fibrosis to their home program: a systematic review. Respiratory Care, 59, 1731-1746. doi: 10.4187/respcare.02990 
Patterson, J. M., Wall, M., Berge, J., \& Milla, C. (2008). Gender differences in treatment adherence among youth with cystic fibrosis: Development of a new questionnaire. Journal of Cystic Fibrosis, 7, 154-164. doi: 10.1016/j.jcf.2007.07.008

Quittner, A. L., \& Espelage, D. L. (1999). Assessing complex family interactions using the daily phone diary. In A. C. Modi, C. S. Lim, N. Yu, D. Geller, M. H.Wagner, \& A. L. Quittner (2006). A multi-method assessment of treatment adherence for children with cystic fibrosis. Journal of Cystic Fibrosis, 5, 177-185. doi: 10.1016/j.jcf.2006.03.002

Quittner, A. L., Modi, A. C., Lemanek, K. L., levers-Landis, C. E., \& Rapoff, M. A. (2008). Evidence-based assessment of adherence to medical treatments in pediatric psychology. Journal of Pediatric Psychology, 33, 916-936. doi: 10.1093/jpepsy/jsm064

Quittner, A. L., Zhang, J., Narynchenko, M., Chopra, P. A., Signorovitch, J., Yushkina, Y., \& Riekert, K. A. (2014). Pulmonary medication adherence and health-care use in cystic fibrosis. Chest, 146, 142-151. doi: 10.1378/chest.13-1926

Rucker, D. D., McShane, B. B., \& Preacher, K. J. (2015). A researcher's guide to regression, discretization and median splits of continuous variables. Journal of Consumer Psychology, 25, 666-678. doi: 10.1016/j.jcps.2015.04.004

Scanfeld, D., Scanfeld, V., \& Larson, E. L. (2010). Dissemination of health information through social networks: Twitter and antibiotics. American Journal of Infection Control, 38, 182-188. doi: 10.1016/j. ajic.2009.11.004

Snaith, R. P., \& Zigmond, A. S. (2012). The hospital anxiety and depression scale manual. London, UK: GL Education Group.

Sundbom, L. T., \& Bingefors, K. (2013). The influence of symptoms of anxiety and depression on medication non adherence and its causes: a population based survey of prescription drug users in sweden. Patient Preference and Adherence, 7, 805-811. doi: 10.2147/PPA.S50055

Taylor-Robinson, D. C., Smyth, R., Diggle, P. J., \& Whitehead, M. (2013). A longitudinal study of the impact of social deprivation and disease severity on employment status in the UK cystic fibrosis population. PloS One, 8, 1-8. doi: 10.1371/ journal.pone.0073322

The Cystic Fibrosis Trust. (2016). UK CF Registry; Reporting and Resources. Retrieved from https://cms. cysticfibrosis.org.uk//the-work-we-do/uk-cf-registry/reporting-and-resources\#

Tierney, S. (2012). Body image and cystic fibrosis: a critical review. Body Image, 9, 12-19. doi: 10.1016/j.bodyim.2011.09.001

Withers, A. L. (2012). Management issues for adolescents with cystic fibrosis. Pulmonary Medicine, 1 , 1-10. doi: 10.1155/2012/134132
Yates, L., Bond, L., Dixon, M., Drew, S., Ferguson, P., Hay, T., ...White, J. (2010). Identity, social connection and education for young people living with chronic illness. Keeping Connected, Young People, Identity and Schooling. Retrieved from http://dro. deakin.edu.au/eserv/DU:30034032/moss-keepingconnected-2010.pdf

Zigmond, A. S., \& Snaith, R. P. (1983). The hospital anxiety and depression scale. Acta Psychiatrica Scandinavica, 67, 361-370. doi: 10.1111/j.16000447.1983.tb09716.x
Weekend/weekday daily treatment adherence in adults with cystic fibrosis 